\title{
Chapter 2 \\ From Tinkering to Practice-The Role of Teachers in the Application of Realistic Mathematics Education Principles in the United States
}

\section{David C. Webb and Frederick A. Peck}

\begin{abstract}
The history of Realistic Mathematics Education (RME) in the United States has positioned teachers at the centre of innovation from its early years to present day. From the first proof-of-concept study at a high school in Milwaukee to localised professional development opportunities, the application and spread of RME is best characterised as a teacher-centred approach to principled reconsideration of how students learn mathematics. Such reconsideration of beliefs and conceptions is often motivated when teachers re-experience mathematics through the lens of progressive formalisation and related didactic approaches. Through a series of cases that articulate teacher interpretation and application of RME in U.S. classrooms, we highlight how teacher participation has led to greater exploration of student-centred practices. These efforts, while inspired and supported by professional development and curricula, have been inspired and sustained by teachers who provide colleagues a proof-of-concept in local contexts.
\end{abstract}

Keywords Design principles • Teacher beliefs • Professional development • Mathematics instruction $\cdot$ Progressive formalisation

\subsection{Introduction}

Mathematics education in the United States is not typically perceived as a field that has demonstrated significant innovation in teaching. Many who experienced mathematics as students speak of the predictability in how it was presented, the boredom, and the limited relevance. "When are we ever going to use this?" is an all-too-common refrain shared by students to their teachers. With great consistency

\footnotetext{
D. C. Webb (凶)

University of Colorado Boulder, Boulder, USA

e-mail: dcwebb@colorado.edu

F. A. Peck

University of Montana, Missoula, USA

e-mail: frederick.peck@umontana.edu 
students' mathematical experience is one that has been described as hard and boring, an unfortunate combination that rarely leads to future pursuits in mathematics. It is in this context that Realistic Mathematics Education (RME), and its design principles for curriculum, instruction and assessment, recast the mathematical experience as one that should be meaningful, relevant, and accessible.

In this chapter, we describe the case of how some teachers in the United States have been influenced by and have benefitted from contemporary Dutch principles of mathematics education, specifically RME. Our collective experience includes professional development, curriculum development, educational research, and the role of the teacher. Even though there are many others who could articulate similar cases about their experience with RME, our stance is focused primarily on the characteristic teacher-centred approach that we have observed and experienced over the past twenty years through which RME was piloted, disseminated, and integrated into various mathematics resources in the United States.

\subsubsection{The Role of Teachers in Advancing RME in the United States}

There are several challenges against advancing mathematics teaching beyond the prevailing transmission model of instruction towards more student-centred approaches that are called for in RME. The challenges that are relevant to this chapter include the apprenticeship of observation, the inherent complexity of ambitious teaching, and the system nature of teaching. While these three constructs are not specific to mathematics education nor education in the United States, these aspects of schooling all involve teachers and the ways in which their classroom practices are envisioned and enacted.

In a classic study of teaching in K-12 schools, Lortie (1975) proposed the hypothesis that teachers emulate practices that they experienced as students. During this 'apprenticeship of observation', which Lortie (1975) estimated at 13,000 hours of observed practice, the role of the teacher and the norms and routines of the classroom are interpreted by future teachers and later imitated. Such recollection of teacher practice, modelled repeatedly, serves as a basis for recreating the surface features of classrooms that the novice teacher has come to value as productive. Continuing the argument, if one's experiences as a student supported his or her success with mathematics (successful enough to pursue a career path into teaching), then those same practices should benefit future generations of students. Historically, with respect to $\mathrm{K}-12$ mathematics teaching, this often led to a mathematics that was predominantly procedural, mechanistic, and predictable. From a case study of secondary schools, a typical day in a mathematics classroom was described as follows.

First, answers were given for the previous day's assignment. The more difficult problems were worked by the teacher or a student at the chalkboard. A brief explanation, sometimes none at all, was given of the new material, and problems were assigned for the next day. The remainder of the class was devoted to working on the homework while the teacher moved 
about the room answering questions. The most noticeable thing about math classes was the repetition of this routine. (Welsh, 1978, p. 391)

What is remarkable is that even though this case study was published almost 40 years ago, the persistence of this routine of review, lesson and practice can be found when observing U.S. mathematics classrooms today despite major policy initiatives and significant resources invested in curricula and professional development. The apprenticeship of observation hypotheses provides one possible (if controversial; see Mewborn \& Tyminski, 2006) reason for this.

From an RME perspective, the prevailing routine of school mathematics reflects what Hans Freudenthal (1983) critiqued as the 'anti-didactical inversion' of teaching the results of mathematical activity, rather than engaging students in the activity itself. Why should problem solving in realistic contexts be presented as an afterthought, deferred until the end of skill and concept development as applications when, historically, authentic problem solving was a motivation for developing new mathematics? From this, the central tenet of RME was born: Mathematics should be thought of, first and foremost, as the human activity of mathematising the world.

Supporting student engagement in authentic problem solving requires new models of teaching. One such model is ambitious teaching (Lampert \& Graziani, 2009), which "requires that teachers teach in response to what students do as they engage in problem solving performances, all while holding students accountable to learning goals that include procedural fluency, strategic competence, adaptive reasoning, and productive dispositions" (Kazemi, Franke, \& Lampert, 2009, p. 11). Ambitious teaching is improvisational, student-centred, and focussed on the development of the full range of learning goals for mathematical reasoning. This resonates with another tenet of RME, in that mathematising the world requires authentic problem solving for students and student-centred instruction by teachers. Ambitious teaching is complex and requires nothing less than a complete overhaul of the prevailing routine in school mathematics.

Changing this routine is challenged by the system nature of teaching (Hiebert $\&$ Grouws, 2007). Teachers' decisions and actions are influenced by a milieu of personal and contextual factors that include teachers' prior experiences (including the apprenticeship of observation), teachers' beliefs about mathematics and about teaching and learning, local curricular policies, available resources, the expectations of the community, and other factors. The opportunity for innovation lies at the nexus of these teacher and context variables. Thus, policies and administrative directives, on their own, are ineffective approaches to motivate changes in practice. Similarly, professional development and other opportunities for teacher learning, on their own, are also insufficient. Sustained innovation in teaching requires systemic changes that align policies, resources, and activities towards common goals.

In the case of RME, the vision for teaching and learning mathematics that was articulated by Hans Freudenthal found political support in the United States in 1989, when the National Council for Teachers of Mathematics (NCTM) published Curriculum and Evaluation Standards for School Mathematics (NCTM, 1989), and related state and national policies were disseminated throughout the United States. The 
vision found further support in curricular resources that were developed using RME for use in the United States (described in greater detail below). Finally, through activities that integrated professional development, classroom practice, and academic research, teachers played a central role in the dissemination and integration of RME in the United States.

\subsubsection{Attractive Features of RME to U.S. Teachers}

From years of observing the use and application of RME at all levels of mathematics, and participating in its implementation, we have developed several hypotheses regarding its uptake by teachers in their classrooms.

First, with respect to curriculum, RME offers a different approach to engage students in new mathematics content. RME's unique context-first approach frequently places students' mathematical engagement on a somewhat level playing field for students from a wide variety of experiences. The use of problem contexts to learn new mathematics provides meaningful anchors for student discussions and mathematical activity. Even though this design principle contradicts many U.S. teachers' prior experiences with mathematics when they were students, the accessibility of mathematical principles when they are situated within carefully selected contexts invites more students to participate and contribute to the mathematical discourse. Mathematically engaged students are a powerful motivator for teachers.

In addition, teachers are attracted to the wide variety of 'pre-formal' models and tools-such as double number lines, percentage bars, and combination charts to support simultaneous calculations with two variables - that are explained as ways to promote progressive formalisation from an RME perspective. In the classroom, these models emerge from realistic activity and are made general though subsequent activity. As such, they serve as powerful resources for students to do mathematics and they invite students to make sense of mathematics (Peck \& Matassa, 2016; Webb, Boswinkel, \& Dekker, 2008). To teachers, these pre-formal models and tools often demonstrate ways in which curricular design can support improved student learning. In professional development, when these models and tools are first used with teachers, we often hear excitement, followed by puzzlement about why this was the first time they were seeing such powerful didactical devices (Webb, 2017).

Finally, RME has been attractive to teachers in the United States due to its robust approach to assessment. Most would recognise that mathematising involves more than working with procedures and algorithms with precision. Mathematising includes several characteristic features that involve modelling, problem solving, inductive and deductive reasoning, developing logical arguments from a set of assumptions, and so forth. To support teachers in achieving these broader goals, RME offers a comprehensive assessment framework (Dekker, 2007; Verhage \& De Lange, 1997). This framework, usually illustrated as an assessment pyramid with three dimensions, has been used by teachers to support students' mathematical reasoning in their classrooms. 


\subsection{Introduction of RME in the United States: Late 1980s - Mid 1990s}

During the 1980s, RME was being articulated in primary and secondary school reforms in the Netherlands. During the latter half of that decade, Thomas A. Romberg, a professor from the University of Wisconsin who was deeply interested in curriculum and policy in mathematics education, was chairing a committee that was putting the final touches on Curriculum and Evaluation Standards for School Mathematics (NCTM, 1989). In the spring of 1988 Jan de Lange, the director of the Freudenthal Institute was invited to meet Romberg at the National Center for Research in Mathematical Sciences Education (NCRMSE) at the University of Wisconsin-Madison. It was a beneficial development that these two mathematics educators with a passion for reforming mathematics teaching and learning, on opposite sides of the Atlantic, would become colleagues and partners. One might observe that such international partnerships are somewhat rare in mathematics education, with few publications co-authored by colleagues from different countries.

The aforementioned NCTM standards articulated a student-centred model of mathematics education oriented around problem solving. In recounting the story as told by Romberg, it was understood that the release of the 'Standards' would be followed soon after with significant support from the National Science Foundation (NSF) for the development of instructional materials, professional development, and multiple systemic initiatives to support the vision for school mathematics. It is worth noting that decades before, Romberg was a graduate student at Stanford working with Ed Begle and the School Mathematics Study Group in documenting how the post-Sputnik New Math materials impacted teaching and learning (an effort, much of which, was also funded by the NSF). So Romberg was no stranger to the need for exemplar instructional materials that could support teacher practice and student learning at scale. In Romberg's (1997, p. 139) opinion, one of the exemplar cases might be found in the work of the Freudenthal Institute, based on the "international reputation arising from the work of Hans Freudenthal and his colleagues.... and the fact that the performance of Dutch students ranked very high on all international comparative studies." This observation led to the first pilot study of RME in the United States-the Whitnall Study.

\subsubsection{The Whitnall Study}

As an outcome of a meeting of various scholars and curriculum developers hosted by Romberg, De Lange proposed a pilot study of RME in a U.S. school. The content focus would be statistics. The school would be Whitnall High School, located in a suburb of Milwaukee. Six teachers and their classrooms would be involved in the study, including Gail and Jack Burrill. Jan de Lange rallied several Freudenthal Institute faculty who moved to the Milwaukee area for four weeks, to work closely 
with the Whitnall High School mathematics department and develop instructional materials based on observed classroom activities from the previous day.

Even though a blueprint for the instructional unit was well-established, regular adaptations were made to the daily activities exemplifying the student-centredness of the approach. As Jack Burrill described the process: "Sometimes we would get copies of that day's lesson the night before. Sometimes the same morning!" (personal communication). Much of the Whitnall Study has been recounted elsewhere (Van Reeuwijk, 1992; De Lange, Burrill, Romberg, \& Van Reeuwijk, 1993). The more important point to make here is that the initial entrée of RME into the United States was through dedicated teachers who were willing to face the unknown, take risks in front of their students and colleagues, and perhaps be humbled in the process. Both Jack and Gail Burrill had vivid recollections of the experience-in fact, one might say the experience was transformative. Gail Burrill recounted her experience in this way:

[T]here was still no real anticipation of the radical changes we would be called on to make in our classrooms. We knew about the NCTM 'Curriculum and evaluation standards for school mathematics'. We were prepared for something new but not so different. As we worked throughout the project, however, the 'Standards' came to life. We began to recognize that we not only needed new ways of teaching but a new way of thinking about the mathematics we should teach. (De Lange, Burrill, Romberg, \& Van Reeuwijk, 1993, p. 154)

One of the main challenges for the teachers was in shifting from a teacher-centred to a student-centred classroom. The materials were designed to support student inquiry; they were not designed for a teacher to show the students how to do the problems. This transition to 'letting the students do the mathematics' was not easy, as wellestablished instructional routines by experienced teachers were found to be difficult habits to break. Eventually, the Whitnall teachers began to internalise the approach used by RME and even began to self-correct their practice. As Jack Burrill recalled, later in the study when he finished teaching a lesson he would meet with the Freudenthal group in the back of the class, and before anything else was said, he would ask, "I blew it again, didn't I?" after recognising that he was doing the mathematics for the students, rather than the having the students to the work.

From a researcher/curriculum developer point-of-view, the experience must have been equally exhilarating. Martin van Reeuwijk was one of the Freudenthal researchers who co-designed materials to be used by the Whitnall teachers. As Van Reeuwijk (1992, p. 516) wrote later in an article summarising the experience:

After the first week of the project, problems with the new mathematics decreased drastically. Students were interested in the class and commented that they liked mathematics now more than before, that it was not so boring, and that they had discovered that mathematics can be used in real-life situations. When questions arose about homework, they came after school to discuss them. Even the low-level and least motivated students got involved in the datavisualisation unit and liked it.

The shift in student engagement and participation observed by Van Reeuwijk did not go unnoticed by the teachers. The students' response to the RME experiment motivated the teachers to emphasise practices that supported student inquiry and problem 
solving. One of the key findings from the Whitnall Study was the importance of teacher professional development and support if RME was going to be implemented at scale in the United States. But this is not a challenge unique to the United States. As described further by Van Reeuwijk (1992, p. 517), "[t]he difficulties that students and teachers had in reaction to a new approach to mathematics were the same as those experienced in the Netherlands when the mathematics curriculum was changed." The difference between the Netherlands and the United States is a student population of over 40 million students.

\subsubsection{Going to Scale with Mathematics in Context}

The Whitnall Study provided a proof-of-concept that RME could work in U.S. classrooms so much so that it motivated Romberg and De Lange to apply for a curriculum development grant at a much larger scale. In the autumn of 1991 the NSF funded the project Mathematics in Context: A Connected Curriculum for Grades 5-8 (MiC), one of thirteen mathematics instructional material development projects funded by NSF in the early 1990s. This project involved a five-year collaboration between research and development teams at the Freudenthal Institute and the University of Wisconsin and scores of elementary and middle school teachers. Focussed on middle grades mathematics, forty units were developed for Grades 5 through 8, which reflected the middle grade band described in the NCTM Standards. Freudenthal researchers were responsible for initial drafts of the units and then these drafts were modified by University of Wisconsin faculty, staff and doctoral students before they were piloted in U.S. schools by teachers and students. To support this work, several Freudenthal researchers moved to Madison, Wisconsin, to work directly with the University of Wisconsin team, and local teachers, as early drafts of the materials were piloted. Given that this project launched before the advent of public email or broadband internet, most communication occurred either in person in Madison, or using transAtlantic mail and conference calls.

As the MiC units moved from piloting to field testing, there was a need to recruit many participating teachers across the United States who worked in a diverse set of school contexts. In addition to a significant number of teachers across Wisconsin, field testing of MiC included teachers in California, Florida, Iowa, Massachusetts, Missouri, Puerto Rico, Tennessee and Virginia. Local site coordinators were also recruited to support ongoing communication between research team and teachers, and coordinate classroom level data collection that could be used to inform subsequent revisions of the student books and teacher guides. Encyclopaedia Britannica agreed to publish the materials, and also supported efforts to market the materials even before they were available in their final printed form. Teachers' response to the field testing of MiC was generally positive; however, the challenges observed in the Whitnall Study suggesting a need to support teachers as they transitioned to student-centred practices were magnified further since there were not as many project personnel who worked locally with teachers on a regular basis. Nevertheless, teachers provided copious 
input from the field, leading to improvements to the student activities and teacher support materials. As the MiC units moved from field testing to the publication of the textbook series Mathematics in Context (National Center for Research in Mathematical Sciences Education \& Freudenthal Institute, 1997-1998), many of the teachers in the original field test sites decided to adopt MiC after they observed its impact on student engagement and achievement (e.g., Webb et al., 2001; Webb \& Meyer, 2002).

Recognition of the need for teacher support led to a commitment on the part of Encyclopaedia Britannica to provide professional development to schools that adopted MiC, which also required the recruitment of lead teachers (many of who piloted and field tested $\mathrm{MiC}$ ) to facilitate workshops across the United States. It was through this rapidly expanding professional development network that early adopters of $\mathrm{MiC}$ were put in the position of communicating RME principles to their colleagues, school administrators, parents and a multitude of teachers who attended MiC workshops. To frame the goals and purpose of MiC, RME was explicitly discussed in these workshops with ample reference to Hans Freudenthal and the historical work of the Freudenthal Institute. Teachers and the co-designers of MiC communicated what RME was, and how it related to the vision of the NCTM Standards. MiC became a U.S. exemplification of RME that demonstrated how formal mathematics could emerge from students' activity in realistic contexts. The careful development of concepts and skills in algebra, number and geometry in $\mathrm{MiC}$ became early instantiations of progressive formalisation, and led others to reference these examples in mathematics education research (Driscoll, 1999; Gutstein, 2003). Towards the end of the 1990s, MiC was referenced in the National Academies Press publication How People Learn (Bransford, Brown, \& Cocking, 1999, p. 137), where it was described as an innovative approach "to the development of curricula that support learning with understanding and encourage sense making”. In this widely disseminated book several key principles of RME have been described in lay terms:

The idea of progressive formalization is exemplified by the algebra strand for middle school
students using Mathematics in Context (National Center for Research in Mathematical Sci-
ences Education \& Freudenthal Institute, 1997-1998). It begins by having students use their
own words, pictures, or diagrams to describe mathematical situations to organize their own
knowledge and work and to explain their strategies. In later units, students gradually begin
to use symbols to describe situations, organize their mathematical work, or express their
strategies. At this level, students devise their own symbols or learn some nonconventional
notation. Their representations of problem situations and explanations of their work are a
mixture of words and symbols. Later, students learn and use standard conventional alge-
braic notation for writing expressions and equations, for manipulating algebraic expressions
and solving equations, and for graphing equations. Movement along this continuum is not
necessarily smooth, nor all in one direction. (Bransford et al., 1999, p. 137)

With respect to contributions to mathematics education research, this period also saw the publication of RME related studies in practitioner journals and highly regarded research journals, which offered many cases of the theory and application of RME in U.S. classrooms. During this time there were also a multitude of classroom-based research studies that used RME related materials. These studies were completed as 
dissertations and focussed on a range of research topics such as curriculum implementation (Brinker, 1996; Clarke, 1995), teacher change (Clarke, 1997), teacher content knowledge (Hutchinson, 1996), student learning (Hung, 1995; Spence, 1997) and classroom assessment (Shafer, 1996; Van den Heuvel-Panhuizen, 1996; Webb, 2001).

\subsubsection{Assessing $R M E$}

Even though MiC was published and competing for adoption in school districts across the United States, requests for additional support came in from school administrators and teachers regarding assessment. Several assessment initiatives emerged during this time, some funded by the publisher to work directly with teacher in New York City and others funded by the U.S. Department of Education, for example, the RAP (Research in Assessment Practices) project and the CATCH (Classroom Assessment as a Basis of Teacher Change) project. These projects involved a team of Freudenthal researchers, including Jan de Lange, Els Feijs, Truus Dekker, Nanda Querelle, Mieke Abels, Martin van Reeuwijk and Monica Wijers. Working together with several researchers from the University of Wisconsin, and teachers in Philadelphia, Providence (RI), and South Milwaukee, this research project studied ways to support teachers' assessment practices. These projects provided an opportunity to articulate the research domain of classroom assessment as it relates to not only RME, but other scholarly literature regarding mathematical literacy, the use of context in task design, non-routine problem solving and formative assessment. All three of the districts had adopted MiC to some extent, but the research also included teachers who were using other NSF-funded curricula or traditional textbooks. The research team worked closely with teachers as they developed their own classroom assessment experiments, which were opportunities to try new and innovative assessment practices. In many cases this involved using assessment tasks that asked for more than recall of procedures, which revealed other forms of students' mathematical reasoning that had previously been under-addressed in quizzes and tests, or classroom instruction. These classroom assessment experiments were transformative experiences for many of the participating teachers, who emerged as leaders in their district and later shared their findings with other mathematics teachers and school administrators at national conferences. Towards the end of the project, greater attention was given to the ways teachers could support student communication, problem solving, and use of representations through formative assessment.

As we entered the new millennium, mathematics education in the United States was amid a public debate over school mathematics and the way it should be taught (Schoenfeld, 2004). A significant outcome of these so-called 'Math Wars' was a call to draw together mathematics educators, research mathematicians and education psychologists to prepare a revision to the 1989 NCTM Standards. The publication Principles and Standards for School Mathematics (NCTM, 2000) subsequently sparked a new wave of revision of NSF-funded instructional materials, and led to a new group 
of lead teachers and schools being engaged in RME through their involvement in the revision of $\mathrm{MiC}$.

\subsubsection{Two Other Collaborations}

Two other productive collaborations are worth mentioning here. The first, 'Math in the City', began as a collaboration between Cathy Fosnot from the City College of New York and Maarten Dolk and Willem Uittenbogaard from the Freudenthal Institute. The project had two goals: to learn more about student learning, and to reform both mathematics teaching and the mathematics curriculum. Teacher participation was integral in achieving both goals. The project was centred on teachers, and over 450 teachers participated in courses and summer institutes designed to allow them to re-experience mathematics as mathematising, and to focus on how children learn mathematics. As well, teachers worked with instructional coaches in their classrooms to develop, test, and tinker with instructional activities. These classroom sessions were recorded, and the videos became data that Fosnot and Dolk used to learn more about student learning. Ultimately, this led to innovative developmental progressions that inscribe student learning as movement within metaphorical 'landscapes' of mathematical strategies, big ideas, and models. The collaboration produced a book series written for teachers that shares the activities and the landscapes of learning produced over the five-year project (Fosnot \& Dolk, 2001a, 2001b, 2002). The books prominently feature vignettes of teachers engaging their students in RME activities. Moreover, the collected activities that emerged from the collaboration were published as Contexts for Learning Mathematics (Fosnot, 2007).

The second collaboration involved Paul Cobb and colleagues in the United States, and Koeno Gravemeijer from the Freudenthal Institute. In the United States, Cobb and colleagues were researching student learning in mathematics classrooms. In looking for heuristics to guide instructional design to promote student learning, they learned about RME and began a collaboration with Gravemeijer to develop, implement, and revise RME-based instructional sequences to promote student learning. In the course of this collaboration, the research team produced instructional sequences for early number (Cobb, Gravemeijer, Yackel, McClain, \& Whitenack, 1997; Gravemeijer, 1999) and statistics (Cobb, McClain, \& Gravemeijer, 2003; McClain \& Cobb, 2001; McClain, Cobb, \& Gravemeijer, 2000). In addition, the team made two conceptual shifts in the ways that they viewed student learning in classrooms and in so doing they provided numerous contributions to research on mathematics teaching and learning (e.g., Cobb, Stephan, McClain, \& Gravemeijer, 2001). Teachers played a large role in these shifts.

The first conceptual shift occurred when the research team began to view classrooms as activity systems, composed of interdependent means of support, including norms, tools, discourse, and activities. This shift was precipitated by a teacher's question, and the research team's realisation that what counted as an 'answer' was an interactional achievement and not an a priori given nor solely a product of an indi- 
vidual student's personal knowledge (Yackel \& Cobb, 1996). In light of this, they shifted their design focus from designing for individual student learning to designing for the mathematical development of classrooms. Because of the central mediating role of teachers in classrooms, this shift entailed a new focus: "[D]evelop[ing] instructional activities that would result in a range of solutions on which the teacher could capitalise as she planned whole class discussions" (Cobb, Zhao, \& Visnovska, 2008 , p. 117). Hence, teachers assumed a central design role in the interactive constitution of classroom activity systems. In addition, the research team came to view a teacher's enaction of instructional sequences as a fundamentally creative activity, arguing "although designed curricula and textbooks are important instructional resources, teachers are the designers of the curricula that are actually enacted in their classrooms" (Visnovska, Cobb, \& Dean, 2012, p. 323, emphasis in original). As they came to recognise the creative role of the teacher, the research team made a second conceptual shift: from designing instructional sequences for teachers to implement, to designing supports for teacher learning.

In light of these conceptual shifts, the research team developed three adaptations to RME design theory: (1) a shift in focus, from designing instructional activities and sequences, to designing entire activity systems-including activity sequences but also social norms and classroom discourse; (2) a shift from designing activities to achieve student learning directly, to designing activities that a teacher can use to achieve a class-wide instructional outcome; and (3) incorporating teacher professional development to support teachers' productive adaptations of designed resources (Cobb et al., 2008).

\subsubsection{FIUS: Developing RME Networks in the United States}

The increasing interest in ways to improve the teaching and learning of mathematics using principles of RME motivated the establishment of the Freudenthal Institute United States (FIUS) at the University of Wisconsin-Madison in 2003. During the early years of FIUS, research proposals were submitted to extend the application of RME into special education and courses typically taught in high schools and community colleges. In 2005, FIUS hosted the first 'Realistic Mathematics Education Conference', which included presentations by Dutch and U.S. researchers and educators describing past, current and emerging use of RME in K-12 curricula, professional development and assessment.

In the autumn of 2005, FIUS relocated to the University of Colorado Boulder. Over the next 10 years, RME was integrated into a number of pre-service and graduate level courses focussed on mathematics and science education, with several of these courses being jointly taught by instructors from the Freudenthal Institute and the University of Colorado Boulder.

In addition, FIUS helped to facilitate several cross-national collaborations involving personnel from the Freudenthal Institute in the Netherlands, FIUS, and U.S. teachers. These collaborations resulted in several classroom studies in middle, high, 
and post-secondary classrooms that were similar in approach to the Whitnall Study. In post-secondary, Monica Geist and other mathematics faculty at Front Range Community College collaborated with Henk van der Kooij to develop a unit that would deepen students' understanding of exponential and logarithmic functions. The implementation of the unit resulted in a dramatic shift in student engagement and mathematical reasoning in ways that were unexpected for a relatively brief two-week unit (Webb, Van der Kooij, \& Geist, 2011). In middle school, a number of productive collaborations were realised. Peter Boon and Mieke Abels worked with middle school teachers in Denver to pilot sequences of applet-based activities organised in the Digital Mathematics Environment. One of the findings from their study was the influence of new contexts and models in the applet sequences; teacher observation of students' productive use of representations resulted in teacher uptake of the same representations during non-tech portions of the unit. A second collaboration involved David Webb from FIUS, Truus Dekker and Mieke Abels from the Freudenthal Institute, mathematics faculty at University of Colorado Boulder, and over thirty teachers in the Boulder Valley (Colorado, U.S.) School District. In this three-year collaboration, teachers designed and redesigned assessments and activity sequences according to RME design principles (Webb, 2009, 2012; Webb et al., 2008). In high school, Fred Peck participated in a series of collaborations with members of the Freudenthal Institute and FIUS as a teacher and researcher.

To give a sense of what these collaborations were like 'from the inside', and the powerful effect that they have for teachers, we now turn to a first-person account of the high school collaborations.

\subsection{Guided Reinvention of High School Mathematics: Fred Peck's Personal Account}

I was introduced to RME during my second year as a high school mathematics teacher, in a school in the Boulder Valley School District. David Webb had just brought FIUS to the University of Colorado. He came to our school for an afternoon, and introduced the mathematics teachers to Peter Boon and Henk van der Kooij, from the Freudenthal Institute. Peter and Henk were interested in collaborating with teachers in the United States. I was interested in reform mathematics education, including active learning and sense-making, but I had very little design experience. After some brief personal introductions, David passed out the 'Hot dogs and lemonade' task shown in Fig. 2.1, and we all got to work.

What was immediately clear to me as I worked on the problem was the principled use of context. Many of my colleagues set up a system of simultaneous linear equations. This was my first instinct, too. But rather than join my colleagues in formal algebra, I found myself drawn to the context. I combined the orders in various ways to make new combinations, eventually eliminating the hot dogs. By that time in my life, I had used Gaussian elimination to solve systems of equations hundreds of times. 
During the summer, many of the residents of Annandale visit Shore Creek Park during the weekend. The park features swimming, boating, bicycling, picnicking and camping.

At Shore Creek Park there is a Hot Dog and Lemonade Stand near the beach. Clara works at the stand on weekends. She has just prepared the two orders below to be served, notice that she writes the prices on the cardboard trays.
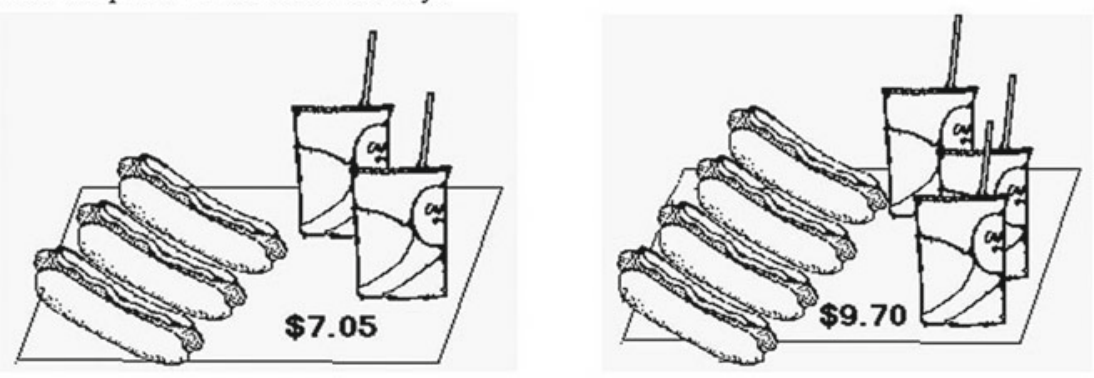

10. How much would it cost for 1 hot dog and 1 lemonade? Explain your reasoning.

11. How much does each hot dog cost? Each lemonade?

12. If Kevin paid $\$ 6.20$ for an order of hot dogs and lemonade, how many hot dogs and how many cups of lemonade should he receive? Show how you found this.

Fig. 2.1 'Hot dogs and lemonade' task (Webb et al., 2001, p. 5)

But I never understood why it worked. Why can one just combine rows of a matrix to make a new row (or combine two equations to make a third equation)? I knew that elimination worked, but had no idea why. And, of course, someone had to teach the method to me. Nothing about a formal matrix or formal system of equations invited exploration or sense-making.

The 'Hot dogs and lemonade' task was different. The context was not just a 'wrapper' for formal mathematics - something to peel away in order to find the system of linear equations hidden within. Of course, the problem could be interpreted that way, but the context invited mathematical exploration. It was begging to be mathematised. As I engaged in realistic activity in the context, making combinations of hot dogs and lemonade, I finally understood elimination! I was hooked. It was clear to me that RME was a powerful tool for didactical design.

The principled use of contexts - that emerged from Freudenthal's (1983) didactical phenomenology_initially drew me to RME. Soon I learned about guided reinvention and emergent modelling/progressive formalisation (e.g., Freudenthal, 1991; Gravemeijer, 1999; Webb et al., 2008), and I became even more excited about RME. Together, didactical phenomenology, emergent modelling, and guided reinvention offered a set of powerful heuristics to design activity sequences such that formal mathematics can emerge from realistic activity.

For the next six years, I endeavoured to apply these design principles to all my classes. Slowly but surely, I developed a repertoire of activity sequences. In Calcu- 
lus, I developed an activity sequence involving see-saws and chains of see-saws to guide students to reinvent the chain rule for derivatives, and another involving the path of a 'vomit comet' as it climbs and free-falls to guide students to reinvent the second derivative as a point of inflection (vomit comets are airplanes that engage in a sequence of free falls followed by steep climbs, and are used to simulate zerogravity). In Probability, I developed activity sequences involving overlapping dart boards and branching rivers to guide students to reinvent joint probability.

I also taught Algebra I with a colleague, Jen Moeller. Jen and I collaborated with David Webb, Peter Boon, and Henk van der Kooij to develop an entire curriculum for Algebra I using RME design principles. We developed a sequence for single-variable equations that guided students to reinvent balance strategies and backtracking strategies, balance models and arrow chain models, and formal expressions as objects to be manipulated and processes to be undone. We developed a sequence for quadratic functions that guided students to reinvent two powerful models for polynomialsan area model and a Cartesian model — and from there to reinvent the fundamental theorem of algebra: that 'line times line equals parabola' and more generally that polynomials are composed of linear factors. Jen and I presented these sequences at local and national conferences (Peck \& Moeller, 2010, 2011).

Another colleague, Michael Matassa, joined our school as a mathematics coach, and he and I started to conduct design research in my classroom. We designed, tested, and refined two local instructional theories using RME: one for fractions as they are used in algebra (Peck \& Matassa, 2016), and one for slope and linear functions (Peck, 2014). We made theoretical contributions to RME, including a deep analysis of the ways that models transform students' mathematical activity and mathematical understandings (Peck \& Matassa, 2016), and a new way of thinking about emergent modelling as a 'cascade of artifacts' (Peck, 2015).

I went to graduate school and wrote my dissertation on RME. I became involved in professional development and conducted workshops for teachers on RME, including emergent modelling and how models transform students' mathematical activity and understanding. Now, I am exploring how cultural theories of learning can contribute to RME, and I am teaching pre-service teachers about RME. I just heard from some former students - now teachers - that they are working together to develop mathematics games using RME design principles.

I still use the 'Hot dogs and lemonade' task.

\subsection{Summary Remarks}

The influence of RME on mathematics education in the United States has been significant. Its approach to the use of context and models has influenced state and national curricula. Models that were used extensively in early RME resources-such as the empty number line, percentage bar and ratio table-were introduced to many teachers in the United States through RME related instructional materials. RME 
is also well represented in mathematics education research published in U.S. and international journals.

There are many other stories that could be shared that describe RME's more subtle influence in the non-public space, such as conversations among teachers, school administrators, and university faculty who are seeking ways to improve student engagement with mathematics or impart a more meaningful mathematical experience to the next generation of students. As mentioned previously, at FIUS and the University of Colorado Boulder, principles of RME have influenced undergraduate mathematics and science education and the design of instructional materials to support active learning. RME has been applied elsewhere in the United States by mathematics faculty who are interested in studying and improving student learning in abstract algebra (Larsen, Johnson, \& Bartlo, 2013), differential equations (Rasmussen \& Kwon, 2007), and other advanced mathematics topics.

In our opinion, what is remarkable about many of these individual stories is the involvement of teachers. From the first pilot study of RME in the United States at Whitnall High to the development of comprehensive curricula, teachers have been central to the dissemination, use, and development of RME in the United States. Teachers have collaborated with researchers to develop and improve RME sequences and curricula, they have become instructional leaders who facilitate professional development on RME, and many continue to participate in the RME communityfor example, by sharing their experiences in using RME at the biennial international conference on RME.

Publications such as Mathematics in Context and Contexts for Learning Mathematics represent the most durable reifications of teachers' participation in RME in the United States. Perhaps even more important, however, are the hidden ways that teachers continue to incorporate RME instructional principles into their classrooms, striving to find meaningful ways to engage students in the human activity of mathematising.

This has been, and continues to be, challenging work. While artefacts of RME have gained wide acceptance in the United States, RME itself is not widely known. Even though Mathematics in Context was adopted by several major school districts in New York City, Philadelphia, and Washington DC, its presense as instructional materials has since waned. The extent to which Contexts for Learning Mathematics is used presently in U.S. schools is also unclear. Thus, while certain models are widely used, the design principles that give the models such power-didactical phenomenology, emergent modelling/progressive formalisation, and guided reinvention-are often unknown to teachers and thus are incorporated only sparingly. In the U.S. academy, RME remains a niche topic of research and development. Mathematics education scholarship, meanwhile, has taken a sociocultural turn, in which learning is understood as an ontological enterprise and not just an epistemic one. There is a need to continue the theoretical development of RME in light of these advances in learning theory.

As we look towards the future, we are hopeful that these challenges will be recognised as opportunities rather than barriers. As they always have, teachers will play a key role in making that vision a reality. 
Acknowledgements We would like to acknowledge the many researchers and teachers who have contributed to the theory and application of RME in the United States, and the vision of Thomas A. Romberg and Jan de Lange to initiate an international partnership that has contributed to mathematics education in numerous ways.

\section{References}

Bransford, J. D., Brown, A. L., \& Cocking, R. R. (1999). How people learn: Brain, mind, experience, and school. Washington, DC: National Academy Press.

Brinker, L. (1996). Representations and students' rational number reasoning (Doctoral dissertation). University of Wisconsin-Madison. Dissertation Abstracts International, 57-06, 2340.

Clarke, B. A. (1995). Expecting the unexpected: Critical incidents in the mathematics classroom (Doctoral dissertation). University of Wisconsin-Madison. Dissertation Abstracts International, 56-01, 125.

Clarke, D. M. (1997). The changing role of the mathematics teacher. Journal for Research in Mathematics Education, 28(3), 278-308.

Cobb, P., Gravemeijer, K., Yackel, E., McClain, K., \& Whitenack, J. W. (1997). Mathematizing and symbolizing: The emergence of chains of signification in one first-grade classroom. In D. Kirshner \& J. A. Whitson (Eds.), Situated cognition: Social, semiotic, and psychological perspectives (pp. 151-233). Mahwah, NJ: Lawrence Erlbaum Associates.

Cobb, P., McClain, K., \& Gravemeijer, K. (2003). Learning about statistical covariation. Cognition and Instruction, 21(1), 1-78.

Cobb, P., Stephan, M., McClain, K., \& Gravemeijer, K. (2001). Participating in classroom mathematical practices. The Journal of the Learning Sciences, 10(1-2), 113-163. https://doi.org/10. 1207/S15327809JLS10-1-2_6.

Cobb, P., Zhao, Q., \& Visnovska, J. (2008). Learning from and adapting the theory of Realistic Mathematics Education. Éducation \& Didactique, 2(1), 105-124.

De Lange, J., Burrill, G., Romberg, T. A., \& Van Reeuwijk, M. (1993). Learning and testing mathematics in context: The case: Data visualization. Madison, WI: National Center for Research in Mathematical Sciences Education.

Dekker, T. (2007). A model for constructing higher-level classroom assessments. Mathematics Teacher, 101(1), 56-61.

Driscoll, M. (1999). Fostering algebraic thinking: A guide for teachers, grades 6-10. Portsmouth, NH: Heinemann.

Fosnot, C. T. (2007). Contexts for learning mathematics. Portsmouth, NH: Heinemann. http://www. contextsforlearning.com/.

Fosnot, C. T., \& Dolk, M. (2001a). Young mathematicians at work: Constructing multiplication and division. Portsmouth, $\mathrm{NH}$ : Heinemann.

Fosnot, C. T., \& Dolk, M. (2001b). Young mathematicians at work: Constructing number sense, addition, and subtraction. Portsmouth, NH: Heinemann.

Fosnot, C. T., \& Dolk, M. (2002). Young mathematicians at work: Constructing fractions, decimals, and percents. Portsmouth, NH: Heinemann.

Freudenthal, H. (1983). Didactical phenomenology of mathematical structures. Dordrecht, the Netherlands: Reidel.

Freudenthal, H. (1991). Revisiting mathematics education: China lectures. Dordrecht, the Netherlands: Kluwer Academic Publishers.

Gravemeijer, K. (1999). How emergent models may foster the constitution of formal mathematics. Mathematical Thinking and Learning, 1(2), 155-177.

Gutstein, E. (2003). Teaching and learning mathematics for social justice in an urban, Latino school. Journal for Research in Mathematics Education, 34(1), 37-73. 
Hiebert, J., \& Grouws, D. A. (2007). The effects of classroom mathematics teaching on students' learning. In F. Lester (Ed.), Second handbook of research on mathematics teaching and learning (pp. 371-404). Charlotte, NC: Information Age Publishing.

Hung, C. C. (1995). Students' reasoning about functions using dependency ideas in the context of an innovative, middle school mathematics curriculum (Doctoral dissertation). University of Wisconsin-Madison. Dissertation Abstracts International, 57-01, 87.

Hutchinson, E. J. (1996). Preservice teacher's knowledge: A contrast of beliefs and knowledge of ratio and proportion (Doctoral dissertation). University of Wisconsin-Madison. Retrieved from ProQuest Dissertations and Theses A\&I (9611421).

Kazemi, E., Franke, M., \& Lampert, M. (2009). Developing pedagogies in teacher education to support novice teachers' ability to enact ambitious instruction. In R. Hunter, B. Bicknell, \& T. Burgess (Eds.), Crossing divides: Proceedings of the 32nd Annual Conference of the Mathematics Education Research Group of Australasia (Vol. 1, pp. 11-30). Palmerston North, NZ: MERGA.

Lampert, M., \& Graziani, F. (2009). Instructional activities as a tool for teachers' and teacher educators' learning. The Elementary School Journal, 109(5), 491-509.

Larsen, S., Johnson, E., \& Bartlo, J. (2013). Designing and scaling up an innovation in abstract algebra. The Journal of Mathematical Behavior, 32(4), 693-711.

Lortie, D. C. (1975). Schoolteacher: A sociological study. Chicago: University of Chicago Press.

McClain, K., \& Cobb, P. (2001). An analysis of development of sociomathematical norms in one first-grade classroom. Journal for Research in Mathematics Education, 236-266.

McClain, K., Cobb, P., \& Gravemeijer, K. (2000). Supporting students' ways of reasoning about data. In M. J. Burke \& R. F. Curcio (Eds.), Learning mathematics for a new century, 2000 yearbook (pp. 174-187). Reston, VA: National Council of Teachers of Mathematics.

Mewborn, D. S., \& Tyminski, A. M. (2006). Lortie's apprenticeship of observation revisited. For the Learning of Mathematics, 26(3), 23-32.

National Center for Research in Mathematical Sciences Education (NCRMSE) \& Freudenthal Institute (1997-1998). Mathematics in context: A connected curriculum for grades 5-8. Chicago, IL: Encyclopaedia Britannica Educational Corporation.

National Council of Teachers of Mathematics. (1989). Curriculum and evaluation standards for school mathematics. Reston, VA: The Author.

National Council of Teachers of Mathematics. (2000). Principles and standards for school mathematics. Reston, VA: The Author.

National Governors Association Center for Best Practices \& Council of Chief State School Officers. (2010). Common core state standards for mathematics. Washington, DC: The Author. Retrieved from http://www.corestandards.org/Math/.

Peck, F.A. (2014). Beyond rise over run: A local instructional theory for slope. Presented at the National Council for Teachers of Mathematics Research Conference. New Orleans, LA, April, 2014.

Peck, F.A. (2015). Emergent modeling: From chains of signification to cascades of artifacts. Presented at the Fifth International Realistic Mathematics Education Conference, Boulder, CO, September, 2015.

Peck, F. A., \& Matassa, M. (2016). Reinventing fractions and division as they are used in algebra: The power of pre-formal productions. Educational Studies in Mathematics, 92, 245-278.

Peck, F.A., \& Moeller, J. (2010) From informal models to formal algebra: Using technology to facilitate progressive formalization in Algebra I. Presented at the Regional Meeting of the National Council of Teachers of Mathematics, Denver, CO, October, 2010.

Peck, F.A., \& Moeller, J. (2011). Length times width equals area and line times line equals parabola: Incorporating two RME models into a cohesive learning trajectory for quadratic functions. Presented at the Third International Realistic Mathematics Education Conference, Boulder, CO, September, 2011.

Rasmussen, C., \& Kwon, O. N. (2007). An inquiry-oriented approach to undergraduate mathematics. The Journal of Mathematical Behavior, 26(3), 189-194. 
Romberg, T. A. (1997). The influence of programs from other countries on the school mathematics reform curricula in the United States. American Journal of Education, 106(1), 127-147.

Schoenfeld, A. H. (2004). The math wars. Educational Policy, 18(1), 253-286.

Shafer, M. C. (1996). Assessment of student growth in a mathematical domain over time (Doctoral dissertation). University of Wisconsin-Madison. Dissertation Abstracts International, 57-06, 2347.

Spence, M. S. (1997). Psychologizing algebra: Case studies of knowing in the moment (Doctoral dissertation). University of Wisconsin-Madison. Dissertation Abstracts International, 57-12, 5091.

Van den Heuvel-Panhuizen, M. (1996). Assessment and realistic mathematics education (Doctoral dissertation). Utrecht University. Utrecht, the Netherlands: CD-ß Press, Center for Science and Mathematics Education.

Van Reeuwijk, M. (1992). The standards applied: Teaching data visualization. Mathematics Teacher, 85(7), 513-518.

Verhage, H., \& De Lange, J. (1997). Mathematics education and assessment. Pythagoras, 42, 14-20.

Visnovska, J., Cobb, P., \& Dean, C. (2012). Mathematics teacher as instructional designers: What does it take? In G. Gueudet, B. Pepin, \& L. Trouche (Eds.), From text to 'lived' resources (pp. 323 341). Dordrecht, the Netherlands: Springer. https://doi.org/10.1007/978-94-007-1966-8.

Webb, D. C. (2001). Instructionally embedded assessment practices of two middle grades mathematics teachers (Doctoral dissertation). University of Wisconsin-Madison. Retrieved from ProQuest Dissertations and Theses A\&I (3020735).

Webb, D. C. (2009). Designing professional development for assessment. Educational Designer, 1(2), 1-26. Retrieved from http://www.educationaldesigner.org/ed/volume1/issue2/article6/.

Webb, D. C. (2012). Teacher change in classroom assessment: The role of teacher content knowledge in the design and use of productive classroom assessment. In S. J. Cho (Ed.), Proceedings of the 12th International Congress of Mathematics Education (pp. 6773-6782). Cham, Switzerland: Springer.

Webb, D. C. (2017). The Iceberg model: Rethinking mathematics instruction from a student perspective. In L. West \& M. Boston (Eds.), Annual perspectives in mathematics education: Reflective and collaborative processes to improve mathematics teaching (pp. 201-209). Reston, VA: NCTM.

Webb, D. C., Ford, M. J., Burrill, J., Romberg, T. A., Reif, J., \& Kwako, J. (2001). NCISLA middle school design collaborative third year student achievement technical report. Madison, WI: University of Wisconsin, National Center for Improving Student Learning and Achievement in Mathematics and Science.

Webb, D. C., \& Meyer, M. R. (2002). Summary report of student achievement data for Mathematics in context: A connected curriculum for grades 5-8. Madison, WI: University of Wisconsin, School of Education, Wisconsin Center for Educational Research.

Webb, D. C., Boswinkel, N., \& Dekker, T. (2008). Beneath the tip of the iceberg: Using representations to support student understanding. Mathematics Teaching in the Middle School, 14(2), $110-113$.

Webb, D. C., Van der Kooij, H., \& Geist, M. R. (2011). Design research in the Netherlands: Introducing logarithms using Realistic Mathematics Education. Journal of Mathematics Education at Teachers College, 2, 47-52.

Welsh, W. W. (1978). Science education in Urbanville: A case study. In R. Stake \& J. Easley (Eds.), Case studies in science education (pp. 383-420). Urbana, IL: University of Illinois. http://files. eric.ed.gov/fulltext/ED166058.pdf.

Yackel, E., \& Cobb, P. (1996). Sociomathematical norms, argumentation, and autonomy in mathematics. Journal for Research in Mathematics Education, 27(4), 458-477. 
Open Access This chapter is distributed under the terms of the Creative Commons Attribution 4.0 International License (http://creativecommons.org/licenses/by/4.0/), which permits use, duplication, adaptation, distribution and reproduction in any medium or format, as long as you give appropriate credit to the original author(s) and the source, a link is provided to the Creative Commons license and any changes made are indicated.

The images or other third party material in this chapter are included in the work's Creative Commons license, unless indicated otherwise in the credit line; if such material is not included in the work's Creative Commons license and the respective action is not permitted by statutory regulation, users will need to obtain permission from the license holder to duplicate, adapt or reproduce the material.

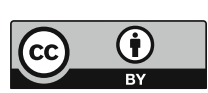

